\title{
5 Selfish bacteria are active throughout the water column of the ocean
}

9 Greta Giljan ${ }^{1}$, Sarah Brown ${ }^{2}$, C. Chad Lloyd ${ }^{3}$, Sherif Ghobrial ${ }^{3}$, Rudolf Amann ${ }^{1}$, Carol Arnosti ${ }^{3}$

11 1) Department of Molecular Ecology, Max Planck Institute for Marine Microbiology,

12 Bremen, Germany

13 2) Program in Ecology, Energy, and the Environment, University of North Carolina-Chapel

14 Hill, Chapel Hill NC USA

15 3) Department of Marine Sciences, University of North Carolina-Chapel Hill, Chapel Hill NC

\section{USA}


19 Heterotrophic bacteria use extracellular enzymes to hydrolyze high molecular weight (HMW)

20 organic matter to low molecular weight (LMW) hydrolysis products that can be taken into the

21 cell. These enzymes represent a considerable investment of carbon, nitrogen, and energy, yet the

22 return on this investment is uncertain, since hydrolysis of a HMW substrate outside a cell yields

23 LMW products that can be lost to diffusion and taken up by scavengers that do not produce

24 extracellular enzymes ${ }^{1}$. However, an additional strategy of HMW organic matter utilization,

25 'selfish' uptake ${ }^{2}$, is used for polysaccharide degradation, and has recently been found to be

26 widespread among bacterial communities in surface ocean waters ${ }^{3}$. During selfish uptake,

27 polysaccharides are bound at the cell surface, initially hydrolyzed, and transported into the

28 periplasmic space without loss of hydrolysis products ${ }^{2}$, thereby retaining hydrolysate for the

29 selfish bacteria and reducing availability of LMW substrates to scavenging bacteria. Here we

30 show that selfish bacteria are common not only in the sunlit upper ocean, where polysaccharides

31 are freshly produced by phytoplankton, but also deeper in the oceanic water column, including in

32 bottom waters at depths of more than 5,500 meters. Thus, the return on investment, and therefore

33 also the supply of suitable polysaccharides, must be sufficient to maintain these organisms.

High molecular weight carbohydrates - polysaccharides - constitute a major fraction of

36 both living and detrital marine organic matter ${ }^{4,5}$. The degradation of polysaccharides depends

37 largely on the activities of bacteria equipped with the extracellular enzymes required to

38 dismantle these often highly complex structures to low molecular weight (LMW) pieces (e.g., $\left.{ }^{6}\right)$.

39 Since LMW hydrolysis products may also be taken up by 'scavengers' that do not produce the

40 enzymes, the enzyme 'producers' that carry out external hydrolysis might benefit only in part

41 from their own enzyme activities ${ }^{1}$. Selfish bacteria circumvent this problem by transporting large 
42 polysaccharide fragments into their periplasmic space, minimizing loss of hydrolysis products ${ }^{2}$.

43 A broad range of polysaccharides is taken up via selfish mechanisms by diverse bacteria in

44 surface ocean waters ${ }^{7}$; the speed and extent of selfish uptake and external hydrolysis vary by

45 geographic location ${ }^{7,8}$, as well as by the nature and abundance of polysaccharides at different

46 phytoplankton bloom stages ${ }^{9}$. The extent to which selfish bacteria are present and active in other

47 depths of the ocean, however, remains unexplored.

Given that polysaccharide-hydrolyzing enzymes are exquisitely specific for substrate

49 structure $^{10}$, we hypothesized that selfish bacteria would be most abundant and active in locations

50 and depths at which freshly produced - structurally unaltered - polysaccharides are common.

51 Since both HMW dissolved organic matter and particulate organic matter are more abundant and

52 are 'fresher' - have a higher fraction of chemically characterizable components - in the upper

53 ocean than in the deep ocean ${ }^{11,12}$, we expected that selfish bacteria would be particularly

54 dominant in the upper water column. We therefore collected water samples at three stations

55 characterized by different physical, chemical, and productivity conditions in the western North

56 Atlantic: in the Gulf Stream, in productive waters off of the coast of Newfoundland, and in the

57 oligotrophic waters of the North Atlantic Gyre (Fig. S1). At these stations, we collected water

58 from the surface, deep chlorophyll maximum (33 to 104 meters), upper mesopelagic ( $\sim 300 \mathrm{~m})$,

59 and bottom (3190 to $5580 \mathrm{~m}$ ). Triplicate incubations were made with water from three different

60 Niskin bottles from each depth (biological replicates). We quantified the presence and activity of

61 selfish bacteria by adding small quantities of structurally-distinct fluorescently-labeled

62 polysaccharides (FLA-PS) and incubating these water samples at in situ temperatures. The added

63 FLA-PS - laminarin, pullulan, fucoidan, xylan, chondroitin sulfate, and arabinogalactan - have

64 different monomer compositions and linkage types. These polysaccharides were chosen because 
65 they are abundant in marine algae and phytoplankton and/or because a wide range of marine

66 bacteria may produce enzymes that hydrolyze them (e.g., $\left.{ }^{13-16}\right)$. We concurrently measured

67 selfish uptake and external hydrolysis rates of the FLA-PS, quantified cell abundances, measured

68 bacterial protein production, and tracked bacterial community composition.

69 Much to our surprise, selfish bacteria were abundant at all water depths that we

70 investigated. These bacteria were identified microscopically by the co-localization of the blue

71 DAPI staining of DNA and the associated intense green staining from the FLA-PS (Fig. 1).

72 Considerable selfish activity was evident even at the t0 timepoint, when $14-17 \%$ of bacteria in

73 surface water, $5-22 \%$ at the DCM, $5-8 \%$ at $300 \mathrm{~m}$, and $5-12 \%$ of bacteria in bottom water took

74 up one of the FLA-PS (Fig. 2a-d). With increasing incubation time, the proportion of cells taking

75 up one of the FLA-PS increased, especially in sub-surface waters. Selfish uptake reached a

76 maximum of $13-18 \%$ of DAPI-stainable cells in surface waters, $14-26 \%$ at the DCM, $12-18 \%$ at

$77300 \mathrm{~m}$, and $25-67 \%$ in bottom water. Uptake at the t0 timepoint reflects the short-term response

78 of the in situ community, since the time elapsed between substrate addition and sample

79 processing is likely insufficient for major changes in community composition, while later

80 timepoints reflect the activities of a community that has changed in composition with time.

81 The in situ bacterial communities showed considerable selfish uptake, despite initial

82 station- and depth-related differences in composition (Fig. 3). These initial communities changed

83 markedly for the most part over the time course of incubation (Fig. 4; Figs S2-S5), but selfish

84 uptake at most stations and depths remained constant or increased after the t0 timepoint. The

85 compositional changes in unamended incubations were very similar to the incubations amended

86 with FLA-PS, demonstrating that the addition of FLA-PS by themselves had little influence on

87 community composition (Figs. S2c-S5c) or cell counts (Fig. S6). Moreover, the changes in 
community composition typically were not convergent for different depths (Fig. S7), in that

89 different genera dominated even in cases where similar classes became more abundant with time.

90 For example, although Gammaproteobacteria became relatively more abundant with time in

91 many of the incubations (Fig. 4, Figs. S2-S5), the dominant phylotypes varied by depth and

92 station (Figs. S8-S10); there were no obvious connections between specific changes in bacterial

93 community composition and selfish uptake.

Although selfish uptake mechanisms have been studied most intensively in members of

95 the gut-dwelling Bacteroidetes ${ }^{17,18}$, our previous investigations in surface ocean waters

96 demonstrated that a range of bacteria, including members of the Bacteroidetes, Planctomycetes,

97 Verrucomicrobia, and the genus Catenovulum (Gammaproteobacteria) carry out selfish

98 uptake $^{7,19}$. Furthermore, a large fraction of the selfish population is still unidentified ${ }^{7,19}$. The

99 observation of selfish activity at multiple depths throughout the water column against a

100 background of changing bacterial community composition suggests that this strategy of substrate

101 acquisition is widespread, and in the ocean is not restricted to a limited range of bacterial taxa.

102 Since selfish uptake cannot be inferred solely from genomic information ${ }^{20}$, however, we cannot

103 yet determine whether selfish uptake mechanisms are as widely distributed as the ability to

104 produce extracellular enzymes to carry out external hydrolysis.

105 We observed remarkable differences in patterns of selfish uptake and external hydrolysis,

106 which were measured in the same incubations. While selfish uptake was measurable for a broad

107 range of polysaccharides at all stations and all depths, external hydrolysis was more variable

108 among stations at similar depths, and decreased sharply in bottom water compared to surficial

109 waters (Fig. 2). In surface waters at Stn. 19, for example, all polysaccharides except fucoidan

110 were externally hydrolyzed, but at Stns. 18 and 20 only laminarin, chondroitin, and xylan were 
111 externally hydrolyzed; these spatial variations in external hydrolysis are consistent with previous

112 observations in surface ocean waters ${ }^{21}$. Station-related variability was also evident at a depth of

113300 m: at Stns. 18 and 20, a broad spectrum of polysaccharides was hydrolyzed, but at Stn. 19,

114 only xylan, laminarin, and pullulan were hydrolyzed. In bottom waters of all three stations, only

115 two or three polysaccharides were hydrolyzed - laminarin and xylan at Stn. 18, laminarin, xylan,

116 and chondroitin at Stn. 19, and laminarin and chondroitin at Stn. 20 - at comparatively low rates,

117 first evident at late incubation timepoints. Overall, the spectrum of substrates hydrolyzed was

118 narrower and the hydrolysis rates in deep water were considerably lower than in surface water,

119 consistent with the few previous reports of polysaccharide hydrolysis in deep ocean waters ${ }^{22-24}$.

120 Patterns of external hydrolysis and selfish uptake at the same stations and depths thus showed

121 striking contrasts.

122 The presence of selfish bacteria in the water column, also at depths well below the

123 euphotic zone, requires new consideration of the economics of substrate processing and uptake.

124 Two-player models of enzyme producers and scavengers have considered the conditions under

125 which extracellular enzyme production may pay off (e.g., $\left.{ }^{1}\right)$, such as when polysaccharides are

126 abundant ${ }^{25}$, or when they are found in sufficiently dense patches ${ }^{26}$. Inclusion of selfish bacteria in

127 this calculus, as described in a new conceptual model ${ }^{27}$, suggests that substrate structural

128 complexity, as well as abundance, needs to be taken into account. Selfish uptake, in which

129 hydrolysate is efficiently captured, can help ensure that investment in extracellular enzymes

130 generates sufficient return. From this perspective, selfish uptake appears to be widespread i)

131 when a substrate is highly complex and requires considerable enzymatic investment, or ii) when

132 there is high competition for a very widely-available substrate, such that competition is a primary

133 consideration. 
The first case covers enzymatic investment to acquire comparatively rare and structurally

135 complex substrates that are selfishly taken up, as in the deep ocean (Fig. 4). Arguably, intact

136 polysaccharides are likely a comparatively rare commodity in most of the subsurface ocean, and

137 thus should be a target for selfish uptake, a consideration that would explain the broad range of

138 substrates selfishly taken up in much of the water column. Polysaccharides such as fucoidan are

139 particularly good examples for a potential pay-off from selfish uptake, since fucoidan hydrolysis

140 requires an extraordinary investment in extracellular enzymes ${ }^{28}$. Moreover, external hydrolysis

141 of fucoidan is comparatively rarely detected in the surface ocean ${ }^{21}$, and to date has not been

142 detected in deep ocean waters ${ }^{29,22-24}$. The second set of circumstances for which selfish uptake

143 pays off - high competition for an abundant polysaccharide - applies especially to laminarin.

144 Oceanic production of laminarin has been estimated to be on the order of 12-18 gigatons

145 annually ${ }^{13,30}$, providing a vast supply of readily-degradable substrate to heterotrophic microbial

146 communities. Moreover, external hydrolysis of laminarin is measurable in almost every site and

147 location in the ocean investigated to date $21,27,22-24,3,7-9$, pointing at extraordinarily widespread

148 capabilities to utilize this polysaccharide. Selfish uptake of this polysaccharide therefore ensures

149 return on enzyme investment by capturing a substrate that would otherwise be acquired by

150 competitors.

151 Here we show for the first time that selfish uptake occurs at multiple depths in the water

152 column, including in deep bottom waters. Furthermore, rapid selfish uptake of polysaccharides in

153 bottom water provides important clues about the physiology of bacteria in the deep ocean, as

154 well as the nature of the substrates that they use. Approximately $5-10 \%$ of the bacterial

155 community at our three deep ocean sites was ready and able to take up specific polysaccharides

156 shortly after addition (Figs. 1-2, Fig. 4). This response is notable in light of the observation that 
157 uptake of a simple amino acid at these depths (as demonstrated by leucine used for bacterial

158 productivity measurements; Table S1), which does not require prior enzymatic hydrolysis, was

159 quite low especially at Stns. 18 and 19. These observations together suggest that a bacterial

160 strategy focused on rapid uptake of structurally more-complex, higher molecular weight

161 polysaccharides pays off in deep water because there is a sufficient supply of these substrates,

162 whereas the in situ inventory of individual amino acids in bottom water is likely too low ${ }^{31}$ to

163 merit special targeting by bacteria. Although we currently lack data on the polysaccharide

164 component of POM in bottom waters, a new method to specifically quantify laminarin in POM

165 has demonstrated a considerable laminarin concentration in POM in the upper water column

166 (including measurements to a depth of $300 \mathrm{~m}^{30}$ ). Moreover, time-variable rapid transport of

167 bacteria/particles to bottom water depths has been demonstrated ${ }^{32}$; some of this organic matter

168 reaching these depths evidently is fresh, and has not been thoroughly worked over in the upper

169 ocean; this organic matter could include intact polysaccharides. Recent measurements of DOM

170 in deep ocean waters additionally suggest that high molecular weight polysaccharides are added

171 to the DOM pool circulating in the deep ocean ${ }^{33}$.

172 Evidence of selfish uptake of highly complex polysaccharides in the deep ocean supports

173 the point that the flux of relatively unaltered organic matter to the deep ocean must be of

174 sufficient magnitude ${ }^{34-35}$ to support a viable and reactive population of selfish bacteria in the

175 deep. The presence of bacteria that are capable of processing complex substrates in a selfish

176 manner also points out that measurements of bacterial metabolism that are dependent upon

177 uptake of monomeric substances have likely underestimated an important fraction of

178 heterotrophic carbon cycling activity, since the enzymatic systems used for selfish uptake are

179 specifically tuned to their target substrates ${ }^{2}$. The prevalence of selfish uptake against a backdrop 
180 of changing bacterial community composition (Fig. 2, Fig. 4, Figs. S2-S5), moreover, suggests

181 that selfish uptake as a substrate acquisition strategy pays off sufficiently that it is comparatively

182 widespread among bacteria. Selfish uptake is important not only in the surface waters of the

183 ocean, but also in the upper mesopelagic and deep ocean, and is carried out by heterotrophic

184 bacteria whose carbon cycling activities help drive much of the marine carbon cycle.

187 Methods

188 i. Station location and seawater collection

189 Seawater was collected at three stations in the western North Atlantic aboard the research vessel 190 Endeavor (cruise EN638) using a sampling rosette of 30-liter Niskin bottles fitted with a Sea-

191 Bird 32 conductivity-temperature-depth (CTD) profiler, between May $15^{\text {th }}$ and $30^{\text {th }} 2019$ (Fig.

192 S1). Collection depths included surface water (2.5-6 m water depth), the deep-chlorophyll

193 maximum (DCM; depth identified via chorophyll fluorescence signal of the CTD: $104 \mathrm{~m}, 33 \mathrm{~m}$,

$19464 \mathrm{~m}$ water depth at Stns. 18, 19, and 20, respectively), 300 m (300 m at Stns. 18 and 20; $318 \mathrm{~m}$

195 at Stn. 19), and bottom water (3,190 m, 4,325 m, and 5,580 m, at Stns. 18, 19, and 20,

196 respectively; Fig. S1).

198 At each station and depth, triplicates of $600 \mathrm{~mL}$ (DCM and bottom water) or $290 \mathrm{~mL}$ (surface

199 and $300 \mathrm{~m}$ water) were added to sterile, acid rinsed $(10 \% \mathrm{HCl})$ bottles and incubated for up to 30

200 days in the dark at in situ temperatures (room temperature (RT) for water from the surface, DCM

201 and $300 \mathrm{~m} ; 4^{\circ} \mathrm{C}$ for bottom water) with one of the six FLA-PS: arabinogalactan, chondroitin

202 sulfate, fucoidan, laminarin, pullulan and xylan, each at $3.5 \mu \mathrm{M}$ monomer equivalent 
concentration. A single live treatment control without the addition of any substrate was included

204 for the DCM and bottom waters; autoclaved killed controls were included for each substrate at

205 each station and each depth, and were incubated under the same conditions alongside

206 polysaccharide incubations

207

208 Subsamples for microbial cell counts and selfish FLA-PS uptake were collected from DCM and 209 bottom water incubations $0,1,3,7$, and 10 days after the addition of polysaccharides; in surface

210 and $300 \mathrm{~m}$ incubations, subsamples were collected $0,3,7,10$, and 15 days after polysaccharide

211 addition. Note also that the t0 timepoint measurements of selfish uptake represent a time period

212 of ca. $30 \mathrm{~min}$ (surface, $300 \mathrm{~m}$ ) to $5 \mathrm{hrs}$ (DCM, bottom water), representing the time required after

213 initial substrate addition to go back and process all of the samples to which substrate had been

214 added. To measure the extracellular hydrolysis of FLA-PS, subsamples were collected on days 0 ,

$2153,7,10,15$, and 30 of the incubations. Subsamples for bulk community analysis were taken

216 before the addition of FLA-PS and at day 1, 3, and 10 of the incubation with DCM and bottom

217 water and at day $0,3,7,10$, and 15 in the surface and $300 \mathrm{~m}$ incubations.

\section{ii. Synthesis of FLA-PS and measurements of extracellular enzymatic activities}

220 Arabinogalactan, chondroitin sulfate, fucoidan, laminarin, pullulan, and xylan were fluorescently

221 labeled with fluoresceinamine (Sigma) and characterized according to Arnosti $(2003)^{36}$.

222 Subsamples $(2 \mathrm{ml})$ were removed at days $0,1,3,7,10,15$, and 30 days post FLA-PS addition,

223 and analyzed after Arnosti $(2003)^{36}$. Note that the added substrate is in competition with

224 naturally occurring substrates, and thus calculated hydrolysis rates are potential hydrolysis rates. 


\section{6 iii. Counts of total and substrate-stained cells}

\section{Cell counts:}

228 To prepare samples, $25-50 \mathrm{~mL}$ of $1 \%$ FA fixed sample were filtered onto a $0.22 \mu \mathrm{m}$ pore size

229 polycarbonate filter at a maximum vacuum of 200 mbar. The DNA of filtered cells was

230 counterstained using 4',6-diamidin-2-phenylindol (DAPI) and mounted with a

231 Citifluor/VectaShield (4:1) solution. A minimum of 45 microscopic images per sample were

232 aquired as described by Bennke et al. (2016) $)^{37}$ with a fully automated epifluorescence

233 microscope (Zeiss AxioImager.Z2 microscope stand, Carl Zeiss) equipped with a cooled

234 charged-coupled-device (CCD) camera (AxioCam MRm + Colibri LED light source, Carl Zeiss),

235 three light-emitting diodes (UV-emitting LED, $365 \mathrm{~nm}$ for DAPI; blue-emitting LED, $470 \mathrm{~nm}$

236 for FLA-PS 488) and a HE-62 multi filter module with a triple emission filter (425/50 nm,

$237527 / 54 \mathrm{~nm}$, LP $615 \mathrm{~nm}$, including a triple beam splitter of 395/495/610, Carl Zeiss) using a 63x

238 magnification oil immersion plan apochromatic objective with a numerical aperture of 1.4 (Carl

239 Zeiss). Final cell enumeration on the acquired images was performed using the image analysis

240 software ACMETOOL (http://www.technobiology.ch and Max Planck Institute for Marine

241 Microbiology, Bremen). Automated cell counts were checked manually.

242

243 Total microbial cell numbers and FLA-PS stained cells were counted in a single experimental

244 setup, following Reintjes et al. $(2017)^{3}$. Counting validation was done through manual cell

245 counting on all stains. Selfish substrate uptake could be measured for only four or five of the six

246 polysaccharides used; at all stations and depths, xylan incubations yielded high background

247 fluorescence, which interfered with cell counting; this problem also affected efforts to count cells

248 for pullulan uptake in surface waters and at a depth of $300 \mathrm{~m}$. Note also that we report the 
249 fraction of cells carrying out selfish uptake under the assumption that each substrate is taken up

250 by different bacteria (i.e., when reporting that for example $22 \%$ of total DAPI-stainable cells

251 were substrate-stained, we add together the percentages taking up laminarin, fucoidan,

252 arabinogalactan, and chondroitin). Since selfish uptake of each substrate is measured in different

253 incubations (triplicate incubations of each individual substrate), however, it is possible that some

254 or all of the cells taking up one substrate also take up another substrate via a selfish mechanism.

255

\section{6 iv. Super-resolution imaging of selfish polysaccharide uptake}

257 The specific substrate accumulation pattern in FLA-PS stained cells was visualized on a Zeiss

258 LSM780 with Airyscan (Carl Zeiss) using a $405 \mathrm{~nm}$, a $488 \mathrm{~nm}$, and a $561 \mathrm{~nm}$ laser with

259 detection windows of 420-480 nm, 500-550 nm, and LP $605 \mathrm{~nm}$, respectively. Z-stack images of

260 the cells were taken with a Plan-Apochromat $63 \mathrm{x} / 1.4$ oil objective and the ZEN software

261 package (Carl Zeiss) was used for subsequent AiryScan analysis.

\section{v. Taxonomic bacterial community analysis}

264 The initial bacterial communities and their change over the course of the incubation were

265 determined through bulk 16S rRNA analysis. Therefore, $25 \mathrm{~mL}$ samples from each incubation

266 were filtered onto a $0.22 \mu \mathrm{m}$ pore size polycarbonate filter at a maximum vacuum of $200 \mathrm{mbar}$,

267 dried and frozen at $-20^{\circ} \mathrm{C}$ until further processing. Total DNA extraction from filter was done

268 using the DNeasy Power Water Kit (Quiagen). Determination of the concentration as well as the

269 size of the extracted DNA was done via gel chromatography using a Fragment Analyzer ${ }^{\mathrm{TM}}$

270 (Advanced Analytical). Amplification of the variable 16S rRNA regions V3 and V4 (490 bp)

271 was done in 30 cycles using the 5 PRIME HotMasterMix (Quantabio) together with the 
272 Bakt_314F (CCTACGGGNGGCWGCAG) and Bakt_805R

273 (GACTACGVGGGTATCTAATCC) ${ }^{38}$ PCR primer pair with an individual 8 bp barcode adapter

274 (based on the NEB Multiplex Oligos for Illumina, New England Biolabs) attached to the forward

275 primer and the reverse primer. The amplified PCR product was purified and size selected using

276 the AMPure XP PCR Cleanup system (Beckman Coulter). Barcoded products were pooled in

277 equimolar concentrations and send for paired-end Illumina sequencing (2x250 bp HiSeq2500) to

278 the Max Planck-Genome-center Cologne. Sequences were merged, demultiplexed and quality

279 trimmed (sequence length 300-500 bp, $<2 \%$ homopolymers, $<2 \%$ ambiguities) with

280 BBTools $^{39}$. The SILVAngs pipeline ${ }^{40}$ with the SSU rRNA SILVA database 138 was used for

281 sequence comparison and taxonomic assignment of the retrieved sequences.

\section{vi. Statistical analysis of bacterial communities}

284 Analysis of the bacterial community composition was done normalized reads representing >

2851,000 reads per sample and the average of triplicates for the FLA-PS amended incubations was

286 used for further analysis and visualization. Archaeal and eukaryal reads were excluded from

287 analysis. Differences in the community composition between station, water depth, incubation

288 time, and substrate amended to unamended incubations were analyzed by analysis of similarity

289 (ANOSIM) and visualized in non-metric multi-dimensional scaling (NMDS) plots, using Bray-

290 Curtis dissimilarity matrices. The community shift over the course of the incubation was

291 visualized by the comparison of the read abundance on genus level from the initial community to

292 the respective read abundance in the incubations over time.

\section{4 vii. Bacterial productivity}


295 Bacterial productivity was measured after Kirchman et al. (2001) $)^{41}$. In brief, bacterial protein

296 production was calculated from leucine incorporation rates, measured in samples that were

297 incubated at in-situ temperatures in the dark for time periods of 12 to $24 \mathrm{~h}$. Bacterial carbon

298 production was calculated by multiplying bacterial protein production by $0.86^{42,41}$.

viii. Data availability

301 Bacterial 16S rRNA gene sequences were archived as Illumina-generated libraries at the

302 European Nucleotide Archive (ENA) of The European Bioinformatics Institute (EMBL-EBI)

303 under the accession number PRJEB45894.

\section{Acknowledgments}

306 We thank the captain and crew of R/V Endeavor, as well as the other members of the scientific

307 party of the EN638 cruise, for excellent work at sea. Andreas Ellrot (MPI Bremen) provided

308 essential support for the microscopic analyses. This project was funded by NSF OCE- 1736772

309 to CA, with additional funding by the Max Planck Society.

\section{Author contributions}

312 Conceived and planned project: CA, RA. Carried out work at sea: GG, SB, CCL, SG, RA, CA. 313 Analyzed samples post-cruise: GG, SB, CCL, SG. Created figures: GG, SB. Wrote manuscript:

314 GG, SB, CA with input from all co-authors. 


\section{References}

319 1. Allison, S.D. Cheaters, diffusion and nutrients constrain decomposition by microbial enzymes in

320 spatially structured environments. Ecol. Lett. 8, 626-635 (2005).

322 2. Cuskin, F. et al. Human gut Bacteroidetes can utilize yeast mannan through a selfish mechanism.

$323 \quad$ Nature 517, 165-173 (2015).

325 3. Reintjes, G., Arnosti, C., Fuchs, B. M. and Amann R. An alternative polysaccharide uptake

326 mechanism of marine bacteria. ISME J. 11, 1640-1650 (2017).

327

328 4. Biersmith, A. \& Benner, R. Carbohydrates in phytoplankton and freshly produced dissolved

329 organic matter. Mar. Chem. 63, 131-44 (1998).

330

331 5. Hedges, J. I. et al. The biochemical and elemental compositions of marine plankton: a NMR

332 perspective. Mar. Chem. 78, 47-63 (2002).

334 6. Hehemann, J.-H. et al. Biochemical and structural characterization of the complex agarolytic 335 enzyme system from the marine bacterium Zobellia galactanivorans. J. Biol. Chem. 287, 30571$33630584(2012)$. 
338 7. Reintjes, G., Arnosti, C., Fuchs, B. M. \& Amann, R. Selfish, sharing, and scavenging

339 bacteria in the Atlantic Ocean: a biogeographic study of microbial substrate utilisation. ISME

$340 J .13,1119-1132(2019)$.

341

342 8. Reintjes, G., Fuchs, B. M., Amann, R. \& Arnosti, C. Extensive microbial processing of

343 polysaccharides in the South Pacific Gyre via selfish uptake and extracellular hydrolysis. Front.

344 Microbiol.11, 3242 (2020a).

345

346 9. Reintjes, G. et al. Short-term changes in polysaccharide utilization mechanisms of marine

347 bacterioplankton during a spring phytoplankton bloom. Environ. Microbiol. 22, 1884-1900

348 (2020b).

349

350 10. Lombard, V., Golaconda Ramulu, H., Drula, E., Coutinho, P. M. \& Henrissat, B. The

351 carbohydrate-active enzymes database (CAZy) in 2013. Nuc. Acids Res. 42, 490-495 (2014).

353 11. Wakeham, S. G., Lee, C., Hedges, J. I., Hernes, P. J. \& Peterson, M.L. Molecular indicators of 354 diagenetic status in marine organic matter. Geochim. Cosmochim. Acta 61, 5363-5369 (1997).

356 12. Benner, R. \& Amon, R. M. W. The size-reactivity continuum of major bioelements in the ocean. 357 Ann. Rev. Mar. Sci. 7, 185-205 (2015). 
359 13. Alderkamp, A. C., Van Rijssel, M. \& Bolhuis, H. Characterization of marine bacteria and the

360 activity of their enzyme systems involved in degradation of the algal storage glucan laminarin. FEMS

361 Microbiol. Ecol. 59, 108-117 (2007).

362

363 14. Haug, A. \& Myklestad, S. Polysaccharides of marine diatoms with special reference to

364 Chaetoceros species. Mar. Biol. 34, 217-222 (1976).

365

366 15. Wegner, C. E. et al. Expression of sulfatases in Rhodopirellula baltica and the diversity of

367 sulfatases in the genus Rhodopirellula. Mar. Genom. 9, 51-61 (2013).

368

369 16. Xing, P. et al. Niches of two polysaccharide-degrading Polaribacter isolates from the North

370 Sea during a spring diatom bloom. ISME J. 9, 1410-1422 (2015).

371

372 17. Koropatkin, N. M., Cameron, E. A. \& Martens, E. C. How glycan metabolism shapes the human gut

373 microbiota. Nat. Rev. Microbiol. 10, 323-335 (2012).

374

375 18. Rakoff-Nahoum, S., Foster, K. R. \& Comstock, L. E. The evolution of cooperation within the gut

376 microbiota. Nature 533, 255-259 (2016).

377

378 19. Giljan, G., Arnosti, C., Amann, R. \& Fuchs, B. M. Seasonal changes in bacterial

379 polysaccharide utilization off Helgoland. Preprint at http:// (2021). 
381 20. Klassen, L. et al. Quantifying fluorescent glycan uptake to elucidate strain-level variability in

382 foraging behaviors of gut bacteria. Microbiome 9, 1-18 (2021).

383

384 21. Arnosti, C., Steen, A. D., Ziervogel, K., Ghobrial, S. \& Jeffrey, W. H. Latitudinal gradients

385 in degradation of marine dissolved organic carbon. PLOS ONE 6, e28900 (2011).

387 22. Hoarfrost, A. \& Arnosti, C. Heterotrophic extracellular enzymatic activities in the Atlantic

388 Ocean follow patterns across spatial and depth regimes. Front. Mar. Sci. 4, 200 (2017).

389

390 23. Balmonte, J. P., Teske, A. \& Arnosti C. Structure and function of high Arctic pelagic, 391 particle-associated, and benthic bacterial communities. Environ. Microbiol. 20, 2941-2954

392 (2018).

393

394 24. Balmonte J. P., Simon, M., Ansgar-Giebel, H. \& Arnosti, C. A Sea Change in microbial

395 enzymes: Heterogeneous latitudinal and depth-related gradients in bulk water and particle-

396 associated enzymatic activities from $30^{\circ} \mathrm{S}$ to $59^{\circ} \mathrm{N}$ in the Pacific Ocean. in press, Limnol.

397 Oceangr. (2021).

398

399 25. Traving, S. J., Thygesen, U. H., Riemann, L. \& Stedmon, C. A. A model of extracellular

400 enzymes in free-living microbes: which strategy pays off? Appl. Environ. Microb. 81, 7385-7393

401 (2015).

402 
403 26. Ebrahimi, A., Schwartzman, J. \& Cordero, O. X. Cooperation and spatial self-organization

404 determine rate and efficiency of particulate organic matter degradation in marine bacteria. PNAS

405 116, 23309-23316 (2019).

406

407 27. Arnosti, C. et al. The biogeochemistry of marine polysaccharides: sources, inventories, and

408 bacterial drivers of the carbohydrate cycle. Ann. Review of Marine Science 13, 81-108 (2021).

409

410 28. Sichert, A. et al. Verrucomicrobia use hundreds of enzymes to digest the algal polysaccharide

411 fucoidan. Nat. Microbiol. 5, 1026-1039 (2020).

412

413 29. Steen, A. D, Ziervogel, K., Ghobrial, S. \& Arnosti, C. Functional variation among

414 polysaccharide-hydrolyzing microbial communities in the Gulf of Mexico. Mar. Chem. 138, 13-

41520 (2012).

416

417 30. Becker, S. et al. Laminarin is a major molecule in the marine carbon cycle. PNAS 117, 6599-6607

418 (2020).

420 31. Giljan, G. et al. Bacterioplankton reveal years-long retention of Atlantic deep-ocean water by the

421 Tropic Seamount. Sci. Rep. 10, 1-11 (2020).

422

423 32. Poff, K. E., Leu, A. O., Eppley, J. M., Karl, D. M. \& Delong, E. F. Microbial dynamics of elevated 424 carbon flux in the open ocean's abyss. PNAS 118, e2018269118 (2021).

425 
426 33. Broek, T. A. B. et al. Low molecular weight dissolved organic carbon: aging, compositional

427 changes, and selective utilization during global ocean circulation. Global Biogeochem. Cycles 34,

428 e2020GB006547 (2020).

429

430 34. Hansell, D. A., Carlson, C. A., Repeta, D. J. \& Schlitzer, R. Dissolved organic matter in the ocean.

431 Oceanography 22, 202-211 (2015).

432

433 35. Bergauer, K. et al. Organic matter processing by microbial communities throughout the Atlantic

434 water column as revealed by metaproteomics. PNAS 115, 400-408 (2018).

435

436 36. Arnosti, C. Fluorescent derivatization of polysaccharides and carbohydrate-containing

437 biopolymers for measurement of enzyme activities in complex media. J. Chromat. B 793, 181-

$438191(2003)$.

439

440 37. Bennke, C. M. et al. Modification of a high-throughput automatic microbial cell enumeration

441 system for shipboard analyses. Appl. Environ. Microbiol. 82, 3289-3296 (2016).

442

443 38. Herlemann, D. P. R. et al. Transitions in bacterial communities along the $2000 \mathrm{~km}$ salinity

444 gradient of the Baltic Sea. ISME J. 5, 1571-1579 (2011).

445

446 39. Bushnell, B. BBTools software package. URL http://sourceforge. net/projects/bbmap 578

447 (2014).

448 
449 40. Quast, C. et al. The SILVA ribosomal RNA gene database project: improved data processing

450 and web-based tools. Nuc. Acids Res. 41, 590-596 (2013).

451

452 41. Kirchman, D. L. Measuring bacterial biomass production and growth rates from leucine

453 incorporation in natural aquatic environments. Methods in Microbiol. 30, 227-238 (2001).

454

455 42. Simon, M. \& Azam, F. Protein content and protein synthesis rate of planktonic marine bacteria. Mar.

456 Ecol. Prog. Ser. 51, 201-213 (1989). 


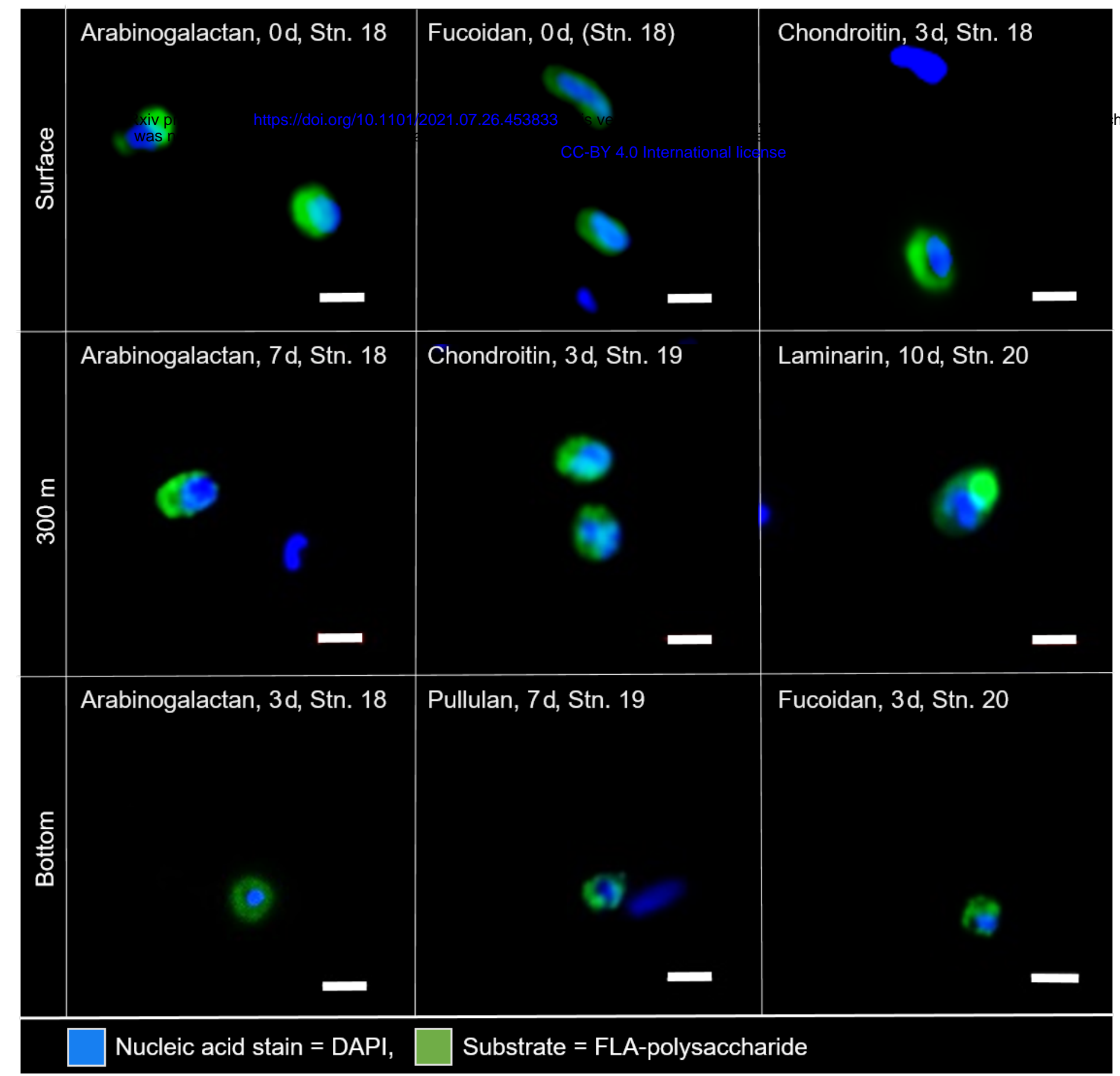

Figure 1 Selfish bacteria throughout the water column in the western North Atlantic Ocean. Superresolution images of microbial cells from surface water, $300 \mathrm{~m}$ water depth, and bottom water $(3,190 \mathrm{~m}, 4,325 \mathrm{~m}$, and $5,580 \mathrm{~m}$, respectively) showing accumulation of fluorescently labeled arabinogalactan, fucoidan, chondroitin sulfate, laminarin, and pullulan due to selfish uptake. Blue signal (DAPI) shows nucleic acids, green signal is due to fluoresceinamine-labeled polysaccharides.

Scale bar $=1 \mu \mathrm{m}$. 

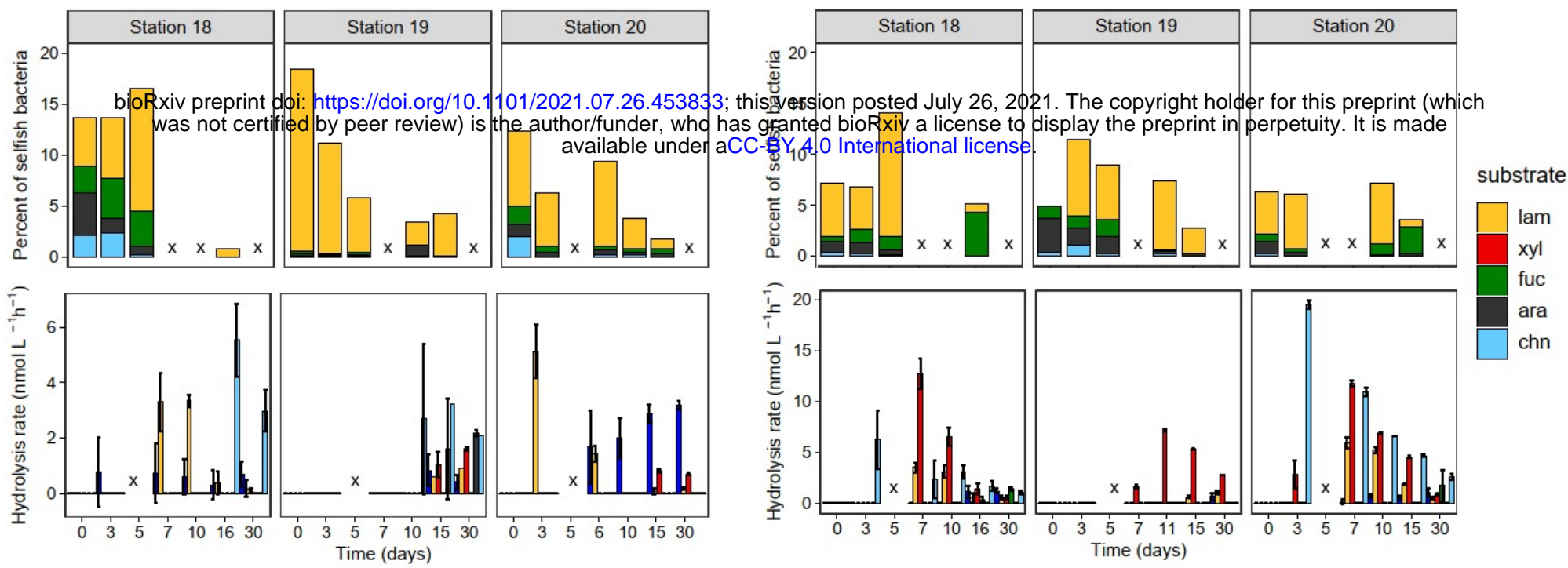
b

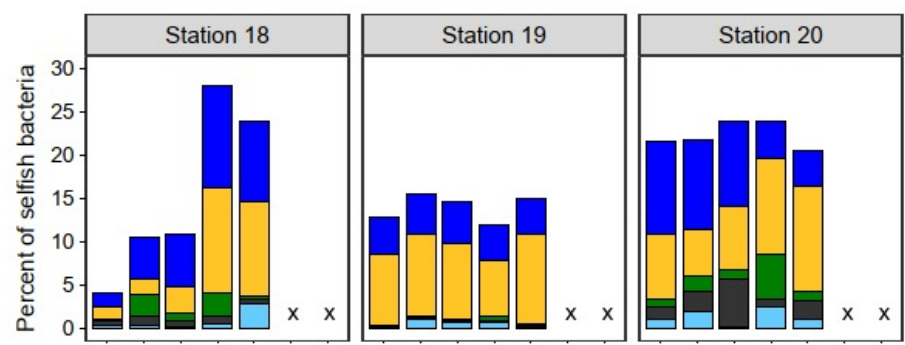

d
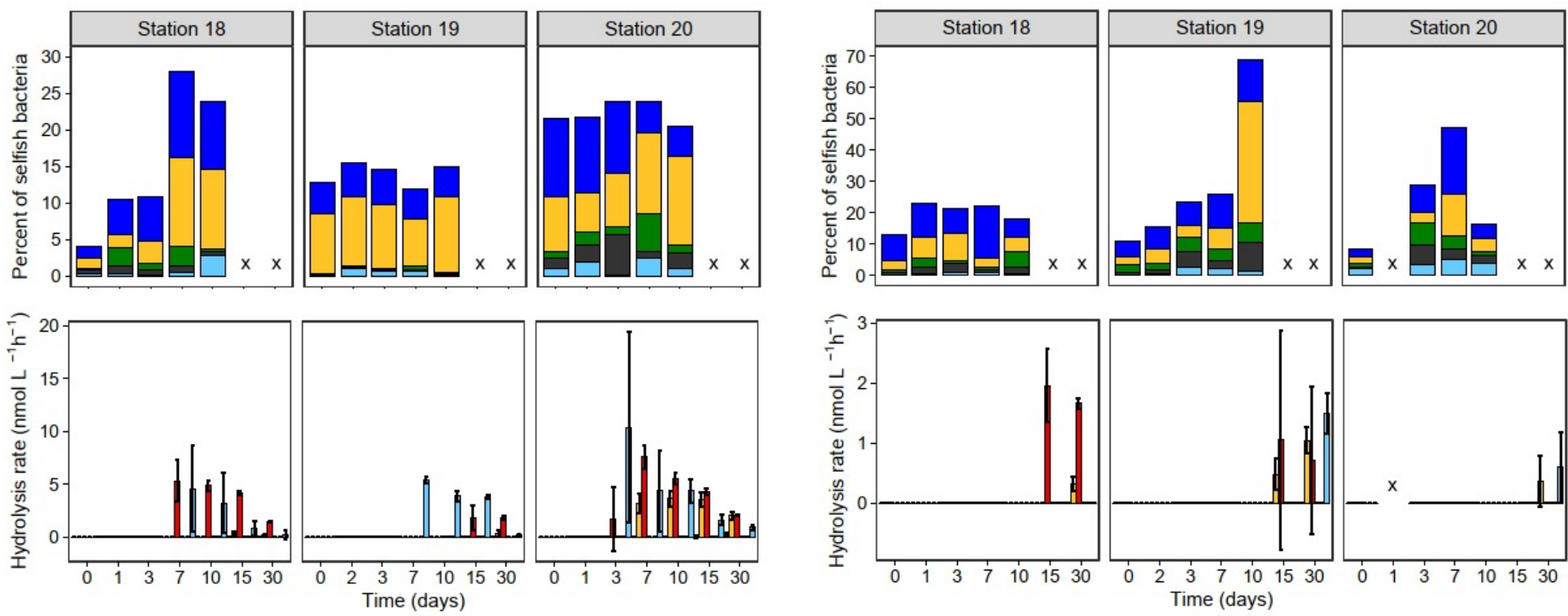

Figure 2 Heterotrophic polysaccharide utilization throughout the water column at three distinct locations in the western North Atlantic Ocean. Selfish uptake and extracellular (external) hydrolysis of six different fluorescently labeled polysaccharides (FLA-PS) in (a) surface waters, (b) at the DCM, (c) at $300 \mathrm{~m}$ water depth, and (d) in bottom waters at Stations 18, 19 and 20 over the course of individual FLA-PS amended incubations. Note that selfish FLA-xylan uptake at all stations and FLA-pullulan uptake in surface waters and at $300 \mathrm{~m}$ depth could not be analyzed due to high background fluorescence and are therefore not included in the data. Error bars represent the average of biological replicates $(n=3)$. Samples marked with an $\mathrm{x}$ were not analyzed. 


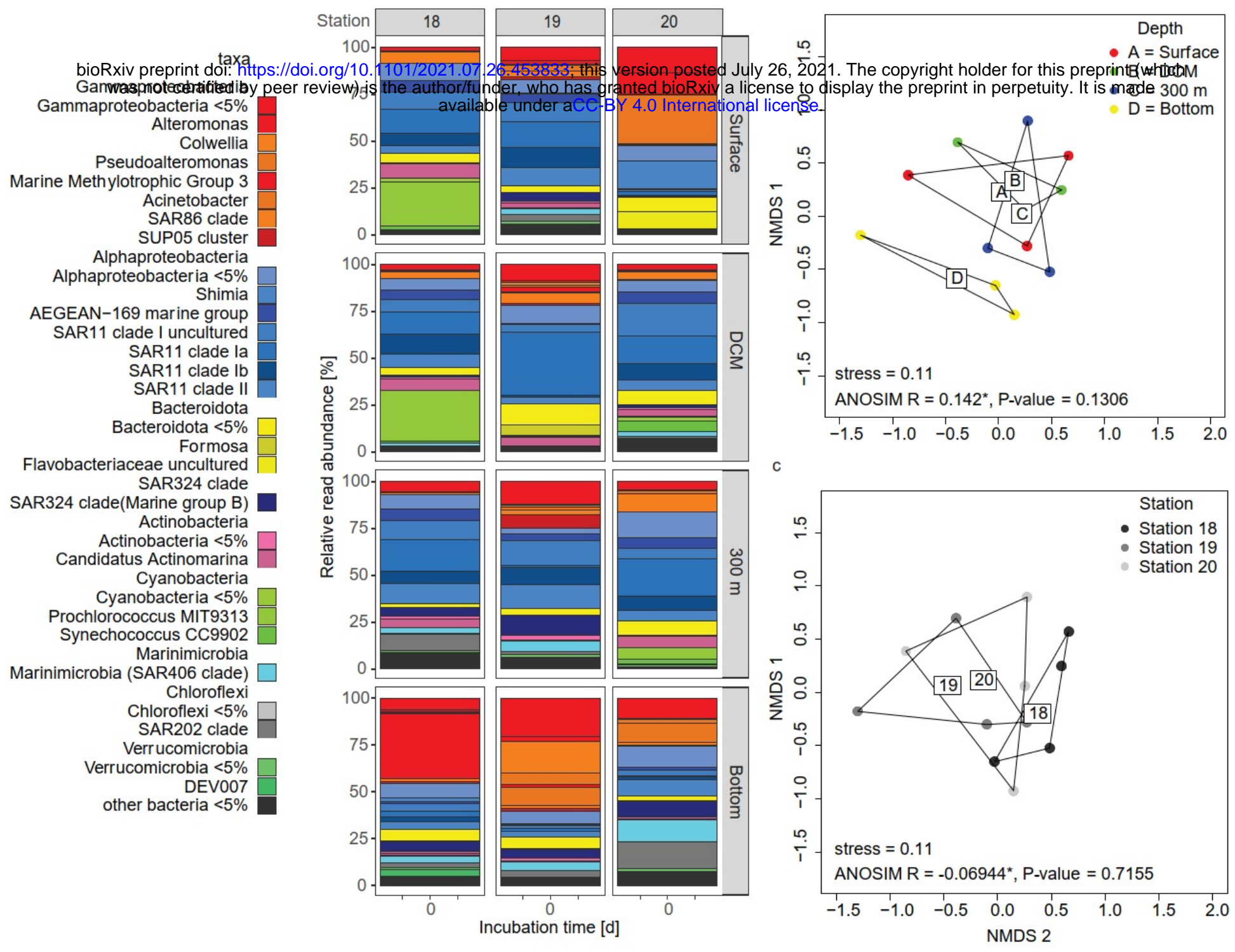

Figure 3 The initial bacterial communities at four depths at three distinct locations in the western North Atlantic. Bacterial communities (a) differ more by (b) depth but are also different by (c) station. * denotes statistically significant results. Each community represents the average of biological replicates $(n=3)$. 
b
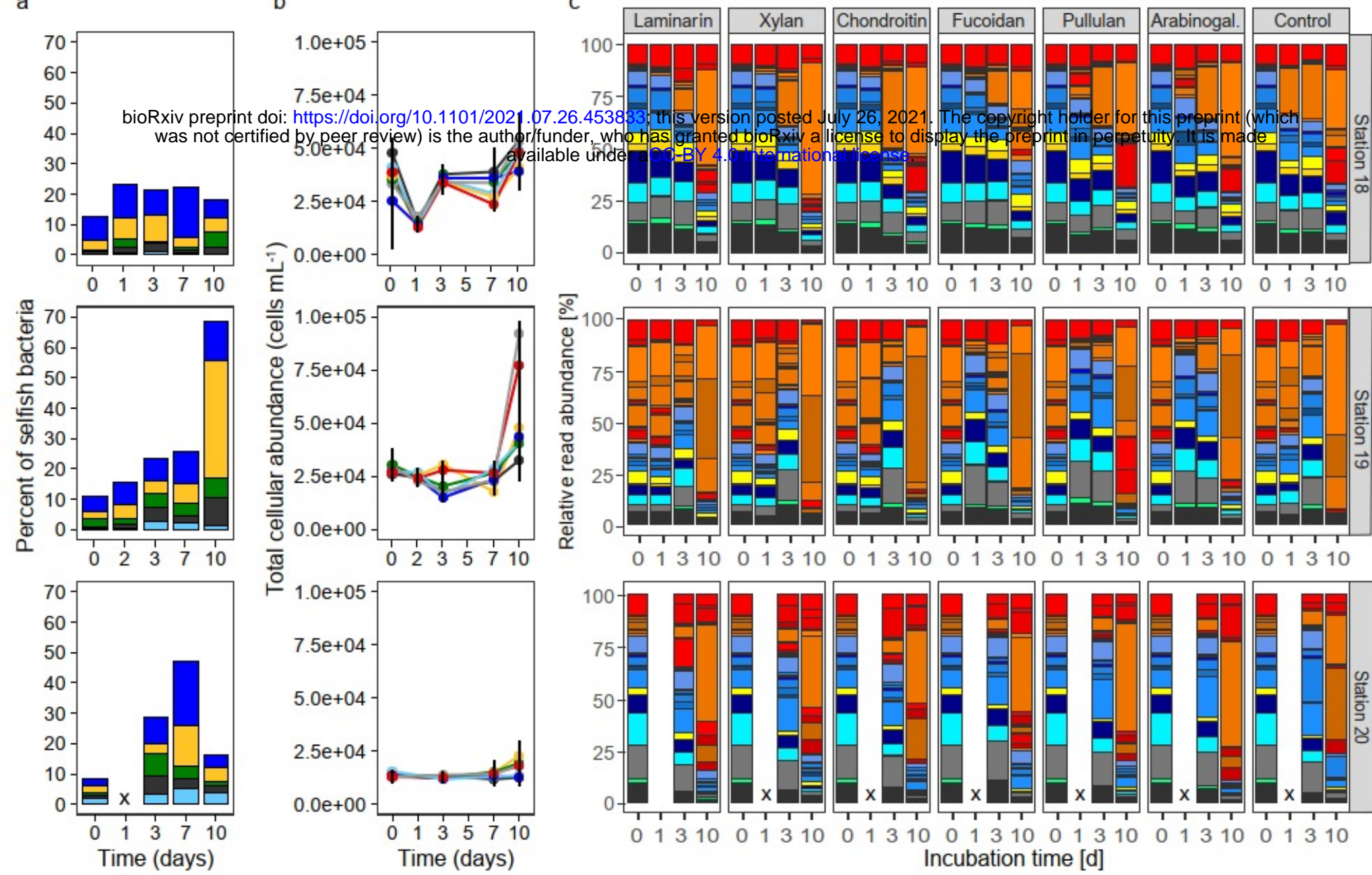

口田
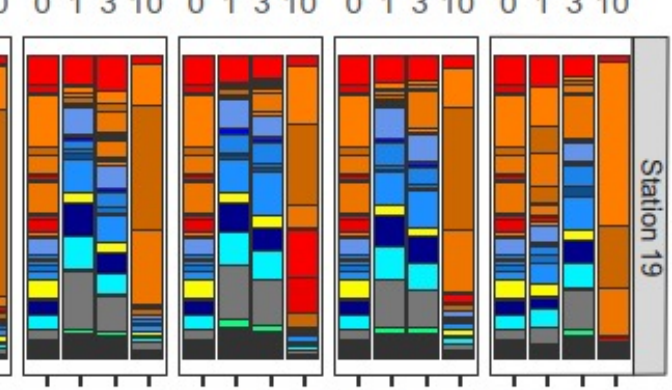

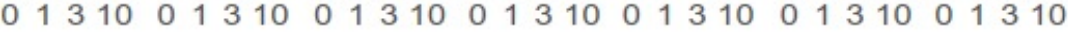

substrate

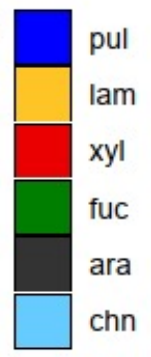

substrate $\rightarrow$ pul taxa

$\rightarrow x y l$

$\rightarrow$ ara

$\rightarrow$ lam

$\rightarrow$ fuc

$\rightarrow$ chn

$\rightarrow$ control
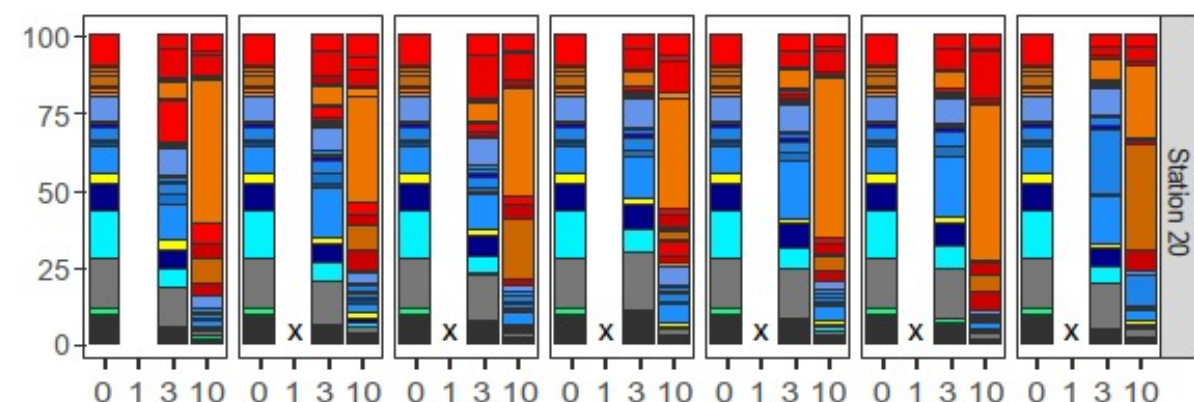

Incubation time [d]

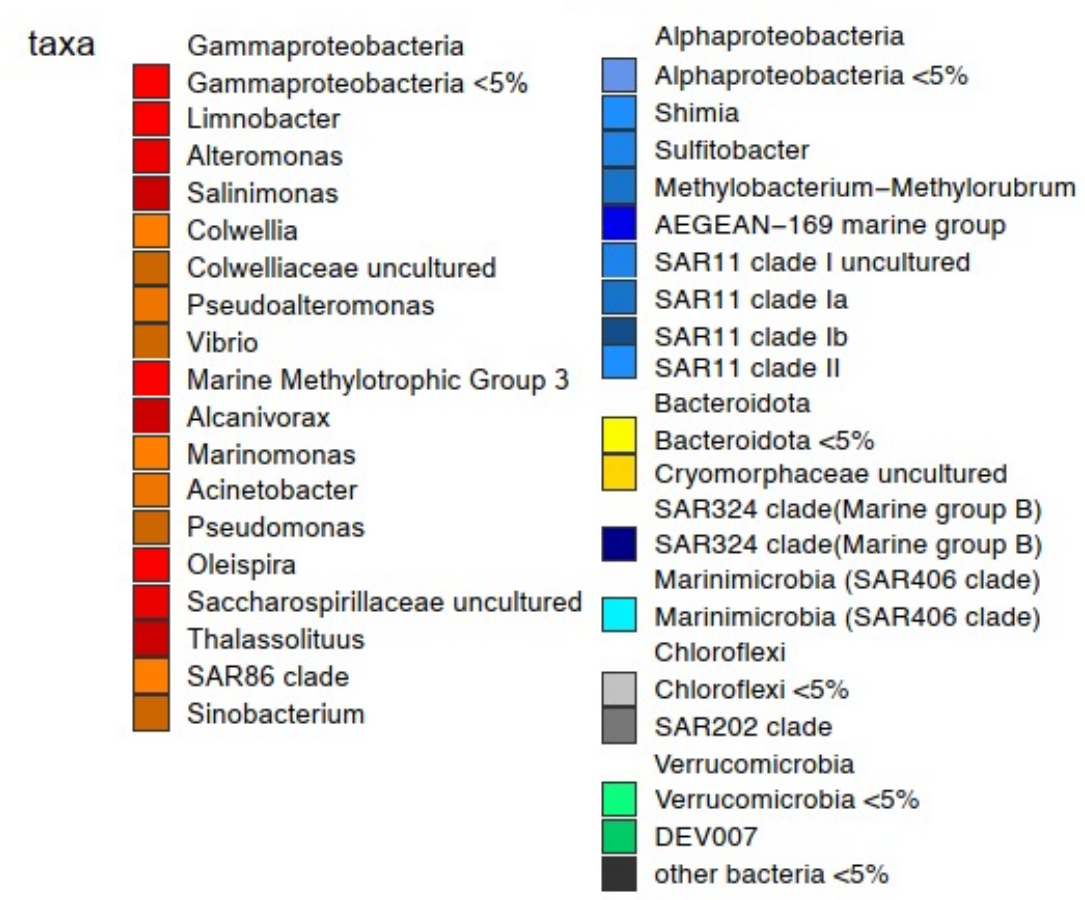

Figure 4 Selfish polysaccharide uptake, cell counts, and bacterial community composition in North Atlantic bottom water. (a) Selfish uptake of FLA-PS over the course of 10 day FLA-PS amended incubations at Stations 18, 19 and 20 (same data as in Fig. 2d). (b) Development of the total microbial cell counts and (c) bacterial community composition in each of the FLA-PS amended incubations from (a), and in the unamended treatment control. The initial community shortly after the addition of the FLA-PS is depicted at 0 days of incubation. Bars represent the average of up to 3 replicates. Time points marked with an $\mathrm{x}$ were not analyzed. 